\title{
Recepción de series sobre narcotráfico en México*
}

\section{Reception of TV Series on Drug Trafficking in Mexico}

\section{Resumen}

Las series sobre narcotráfico han sido objeto de debate, producto de sus contenidos, sin embargo, no hay estudios sobre su recepción entre los espectadores mexicanos. Esta investigación, de corte cualitativo, busca conocer la opinión de los jóvenes mexicanos respecto a este tipo de seriados. Se concluye que los televidentes reciben gratificaciones de entretención e información, a la vez que infieren una crítica a las instituciones gubernamentales.

Palabras claves

televisión, narcotráfico, análisis cualitativo, recepción, corrupción.

\begin{abstract}
TV series on drug trafficking have been subject of debate due their contents; however, there are no studies about the Mexican audience's reception of them. This qualitative research seeks to know the opinion of the Mexican youth regarding this type of series. It is concluded that viewers receive entertainment and information bonuses, while also infringing criticism on governmental institutions.
\end{abstract}

"Este artículo es resultado de una investigación realizada en el Colegio de Letras Modernas de la FFyL, UNAM. Los autores de este artículo son: Ainhoa Vásquez Mejías (coordinadora del proyecto), Alba López Gamboa (albadaniela.lg@gmail.com), Alejandro Corona Ocehlo (alex_breck26@hotmail.com), Andrés Aguilar Rosales (andydelrey27@gmail.com), Dolores Katsougris (lolakats72@gmail.com) y Paula Córdova García (paulacordovag11@gmail.com) 


\section{Introducción}

Desde hace un poco más de diez años, la emisión de programas de ficción respecto al narcotráfico ha sido objeto de cuestionamiento por parte de periodistas, autoridades, padres de familia y televidentes. La colombiana Sin tetas no hay paraíso, transmitida por Caracol TV y cuyo primer capítulo fue emitido el 16 de agosto del 2006, constituyó un cambio en el modelo de telenovela tradicional, a la vez que suscitó gran polémica por su contenido. La muchacha que ascendía socialmente mediante el matrimonio fue reemplazada por Catalina, la protagonista de Sin tetas no hay paraíso, una joven que aspiraba a salir de su pobreza transformándose en amante de algún narcotraficante y, para ello, fantaseaba con una cirugía plástica que incrementara sus senos.

Esta primera producción de 23 capítulos, si bien tuvo mucho éxito de audiencia -ganó seis premios India Catalina, dos premios TVyNovelas y los derechos fueron vendidos a la cadena española Telecinco (la que produjo su propia versión de dos temporadas) y a la televisora Telemundo- también fue objeto de múltiples críticas por parte de periodistas, políticos y académicos. Eric Duport, presidente de la Cámara de Comercio de Pereira, por ejemplo, señaló para la Radio $\mathrm{W}$, que este tipo de producciones explotaban el morbo valiéndose de estereotipos, por lo que atentaban contra la dignidad de las pereiranas (Monroy y Cabrera). Académicas como Pobutsky y Aguirre cuestionaron, asimismo, los roles de género exhibidos en esta producción, analizando el impacto que podría tener para las jóvenes en contextos de narcotráfico, una protagonista con deseos de moldear su cuerpo para convertirse en objeto sexual.

A esta primera ficción referente al mundo del narcotráfico, se sumaron nuevos éxitos colombianos como El cártel de los sapos (2008), Las muñecas de la mafia (2009) y Escobar, el patrón del mal (2012), así como producciones 
mexicanas que han tenido un gran impacto en el público, como La reina del Sur (2013), El señor de los cielos (2013-2019), Señora Acero (2014-2019), entre otras. El debate respecto a sus contenidos también ha ido en aumento, con mayoría de opositores en los ámbitos académicos y políticos y gran número de espectadores según las cifras de rating. Entre los detractores, destaca la campaña para detener su transmisión en TV abierta, impulsada por los políticos Lía Limón y Zoé Robledo y la Asociación A favor de lo mejor, en el año 2016, quienes argumentaron que estas realizan una apología a la violencia. Sin embargo, a pesar de ser un producto bastante condenado, hasta ahora, no se le ha preguntado a los receptores mexicanos por qué consumen estas series y qué critican o rescatan de ellas. Es así que, como equipo, nos interesa subsanar este vacío y centrarnos en los destinatarios, rescatando sus opiniones, principalmente, en los ámbitos de: gratificación, paradigmas de género, representación de las instituciones gubernamentales y posible enseñanza que deja este tipo de programas.

Esta investigación, así, no parte de una concepción negativa preestablecida, lo que nos aleja de estudios cualitativos sobre narcotelenovelas realizados en otros países Latinoamericanos, los que tienden a asumir que son productos dañinos para la población. Como equipo, consideramos que estas no son nocivas per se y que, incluso, en sus guiones podemos encontrar contenidos positivos que se transmiten a los televidentes, por ejemplo, muchas series de este tipo derrocan estereotipos de género y abordan problemas actuales respecto a la sexualidad. Como muestra de ello, en El Dandy (2015), los personajes masculinos hablan de eyaculación precoz, violación entre hombres y de homosexualidad en el narcomundo; así como en Falsa identidad (2018), se realiza una crítica aguda a la violencia contra las mujeres, a la vez que se propone una masculinidad corresponsable, tanto en la crianza de los hijos como en las labores domésticas, pues, es Diego quien asume el cuidado del hogar: "eso no me hace menos macho, al revés me hace un macho pecho peludo, que lava mejor los platos que cualquiera" (cap. 8), le dice a su hijo adoptivo.

A la par, creemos que las series sobre narcotráfico, además de proponer nuevos modelos de género, realizan una crítica al consumo de drogas: la hija menor 
de Aurelio Casillas en El señor de los cielos (temp. 3) se convierte en adicta, lo que hace reflexionar a su hermana Rutila y salirse del negocio. Asimismo, cuestionan el rol de las instituciones públicas en el éxito de esta industria. En estas producciones, el narcotráfico no es privativo de criminales sanguinarios, sino una red que incluye a empresarios, políticos y policías. Finalmente, al ser producciones cercanas al melodrama, habría cierto componente ético que se revela en relación al castigo, pues los villanos reciben el final que merecen: muerte o cárcel; demostrando que los malos, sean narcos o mandos corruptos, deben pagar por sus delitos. Esta opinión, sin embargo, no es compartida por gran parte de los académicos del área, tal como demostraremos.

\section{Estado de la cuestión}

Si bien, hasta ahora no existen estudios acerca de la recepción que tienen este tipo de productos en México, hay algunas investigaciones de tipo cualitativo en otros países de Latinoamérica que, por lo general, parten de una consideración negativa respecto a las series sobre narcotráfico. Ximena Manrique, por ejemplo, busca determinar la percepción sobre el narcotráfico en los jóvenes colombianos, a través del análisis de Escobar, el patrón del mal y El Capo (2009-2010). Para ello recurre a dos focus groups, con participantes elegidos aleatoriamente de entre $16 \mathrm{y}$ 19 años y 19 y 25 años, a los que se les muestra el fragmento de un capítulo en que la mamá de Escobar aconseja "El día que usted haga algo malo, hágalo bien hecho, no sea tan pendejo de dejarse pillar" (cap.1).

Alejandro Sánchez y Valentina García, por su parte, realizan un análisis sobre la percepción de jóvenes de sexo masculino, entre los 18 y 25 años, estudiantes de la Pontificia Universidad Javeriana Cali, en relación con las representaciones de las masculinidades en El cártel de los sapos (2008). Similar al método utilizado por Manrique, se les muestra un video de 10 minutos en el que expresamente se revela una actitud patriarcal para compararla con las opiniones de los entrevistados: "La mayoría de los hombres participantes están de acuerdo en que, en caso de infidelidad, serían capaces de agredir o incluso matar a la mujer que 
les fue infiel" (63). Concluyen que los jóvenes se identifican con los personajes, por cuanto presentan actitudes machistas, adoptan el léxico y la manera de vestir de los capos. La duda que nos surge a partir de este estudio es si, efectivamente, hay una correlación directa entre el machismo y el ver una serie sobre narcotráfico y si no es, más bien, la serie un reflejo de la sociedad patriarcal.

Laura Pérez, realiza encuestas a 123 jóvenes de entre 15 a 17 años en el Colegio Consejo Provincial de Quito. Su hipótesis es que "el aumento de las transmisiones de narco novelas en nuestro país, sin horario y sin moderación en su contenido grotesco ha generado un gran impacto en las jóvenes de 15 a 17 años que habitan en el sur de la ciudad de Quito" (64). Algunas de las preguntas que constituyen su método son ¿Ha notado un cambio en su comportamiento (forma de hablar, vestirse, etc.) al ver una de estas novelas? ¿Realiza actividades relacionadas con este tema? ¿Cree que gracias a los temas tratados en estas telenovelas ha aumentado la delincuencia, sicariato, etc.? Resulta interesante señalar que, según su encuesta, sólo el 50\% respondió haber visto alguna narcotelenovela y que el 54\% considera que estos productos han colaborado en el aumento de la delincuencia. Se concluye que estos productos no presentan elementos positivos y que, al contrario, propician la existencia de narcotraficantes.

Danixa Martínez y María Fernanda León, analizan el impacto de la narcotelenovela El señor de los cielos, entre los jóvenes de 15 a 17 años en Guayaquil. Para ello seleccionaron a 51 adolescentes que tuvieran noción de la existencia de este tipo de programas, no obstante, sólo un 36\% reconoció ver esta serie en particular. Aunque son pocos los receptores asiduos a ella, la mayoría de los encuestados considera que crea estereotipos, enaltece las labores del narco, justifica el delito y persuade el pensamiento de los niños, por lo que las autoras concluyen que los jóvenes ven El señor de los cielos como un ejemplo y quieren seguir sus pasos.

Bastante similar resulta la investigación de López, Vaque y Arias, quienes intentan analizar la influencia de las narcotelenovelas en el consumo de drogas en los adolescentes, entre 15 y 17 años, en la cooperativa Unión de Bananeros del 
Guasmo Sur de Guayaquil. Los jóvenes señalan conocer las narcotelenovelas, sin embargo, poco más del 50\% reconoce haber visto, al menos, una. Entre los resultados del estudio destacan que el $81.86 \%$ de los encuestados considera que fomentan la delincuencia y el crimen organizado; el $74.10 \%$ cree que debieran ser consumidas por mayores de 18 años; sólo el 10,36 \% se ha identificado con algún personaje y un "bajo porcentaje de adolescentes que se sienten motivados a consumir o comercializar drogas después de ver narconovelas" (en línea). No obstante, los investigadores concluyen que ver narcotelenovelas es nocivo para los adolescentes, por cuanto, los encuestados consideran que crean patrones de conducta.

Jenny Moreno, por otra parte, plantea como hipótesis que "existen diferencias entre las formas de recepción y apropiación de las narcotelenovelas por parte de los jóvenes de los diferentes sectores socioculturales" (39). Para comprobarlo selecciona a 12 jóvenes bogotanos, entre los 12 y los 16 años, pertenecientes a un colegio público y otro privado. Concluye que, mientras los jóvenes de clase social baja sienten mayor empatía por los personajes, los de clase alta expresan que no se identifican con ellos, pues los consideran malvados y grotescos. Asimismo, los jóvenes del colegio privado incluyen a los políticos y policías como parte de la corrupción.

Claudia Cárdenas, al igual que Moreno, busca demostrar la influencia de las narcotelenovelas, según condición socioeconómica, en adolescentes entre 13 y 15 años de un colegio privado y un colegio público de Cuenca. De cada colegio seleccionó ocho participantes para un focus group. Entre los resultados cabe destacar que el 52,7\% conoce sobre las narcotelenovelas, por lo que se advierte que "no es un espectáculo de moda hoy por hoy entre los adolescentes encuestados" (47). Los resultados no difieren, en este caso, por condición social, pudiendo resaltar argumentos generales. Por ejemplo, los jóvenes consideran que hay castigo (muerte y cárcel) para los actos violentos, lo que "nos permite conocer que los adolescentes están conscientes de los castigos que se aplican para sancionar a los narcotraficantes" (60), vinculado a que, para ellos, los policías son los héroes de 
estas historias, mientras los capos son villanos. Respecto al componente de género, la mayor parte de los jóvenes cree que las narcotelenovelas muestran a las mujeres como objeto sexual, pero son capaces de realizar una crítica a esta forma de representación.

Montoya, Guarín y García, buscan indagar en la recepción de productos relacionados al narcotráfico en estudiantes de un colegio específico. Las conclusiones generales es que los jóvenes no admiran ese tipo de vida porque "eso es una vida sin ilusiones y sin metas" (68) y cuyo único fin es la muerte violenta: "preferiría perder un minuto de mi vida que no perder mi vida en un minuto" (68), así como, que la imagen de género que presentan desfavorece a las mujeres. Frente a la pregunta de si les deja alguna enseñanza afirman: "Que no debemos maltratar a las mujeres" (80), "El narcotráfico es malo porque puede causar muchas muertes" (80). El $61 \%$ asegura que aprendió que el narco es malo, el $15 \%$ que se debe ir por el camino del bien y $8 \%$ a no maltratar a las mujeres. El $85.1 \%$ afirma, además, que no le gustaría vivir de ese modo.

Aunque de estos trabajos rescatamos ciertas conclusiones y respuestas positivas por parte de los entrevistados, todos los estudios realizados coinciden en su intento por demostrar que estos productos televisivos son nocivos para la población, especialmente, para los jóvenes. Como señalábamos, nuestra investigación no comienza desde una mirada negativa, sino que rescata ciertos aspectos positivos, al menos, en cuanto a sus guiones ${ }^{1}$. No obstante, intentamos no dirigir las preguntas hacia una confirmación de nuestra opinión, así como elaborar una encuesta transparente que nos diera ciertas directrices respecto a la forma en que el público mexicano recibe estos seriales.

\footnotetext{
${ }^{1}$ Nuestra formación académica, en el terreno de la literatura, nos permite sólo realizar un análisis respecto a los guiones de estas producciones. Estamos conscientes, sin embargo, de que también es necesario realizar estudios profundos en torno a las imágenes que reproducen.
} 


\section{Metodología}

\section{a) Acerca de la elección del concepto "series sobre narcotráfico"}

En las investigaciones académicas, referidas con anterioridad, se privilegia el uso del término "narcotelenovela" para mencionar este tipo de narrativas televisivas, sin embargo, académicos y periodistas, utilizan también, con frecuencia, el concepto de "narcoseries". En general, ambos términos se usan de manera intercambiable, puesto que, en efecto, este género televisivo presenta elementos que podrían responder a ambos formatos: a la telenovela tradicional y a las series. Rosemary Huisman, en su libro Narrative and Media, señala que la soap opera posee una estructura narrativa similar a la telenovela, por cuanto: "dialogue, rather than action is the usual nature of interaction in the soap opera genre (compare the usual 'interaction' of violence in the genre of action drama), this means that talk between characters is the main of the soap opera narrative" (184). Tal como ocurre en las telenovelas tradicionales, los diálogos y las introspecciones de los personajes son lo que impulsa la trama.

Por otra parte, la académica Marcia Trejo ha definido a la telenovela, de la siguiente forma: "es un melodrama televisado cuya historia se cuenta en capítulos o episodios seriados que deben seguirse consecutivamente para comprenderla. Por lo general gira en torno a una línea amorosa y una serie de dramas e intrigas que se estructuran con la intención de generar suspenso y así garantizar el seguimiento de la anécdota" (27). A esta definición debemos agregar que uno de sus rasgos fundamentales es el énfasis dado a la moralidad-expresado en la lucha entre el bien y el mal-y que, tras muchas peripecias, consigue triunfar ante el vicio. Es por ello que los personajes son opuestos, representando una contraposición de valores: héroe-heroína y villanos, sin que exista entre ellos ninguna conciliación (Trejo 43).

En este tipo de seriados permanecen ciertos aspectos de la telenovela, aunque matizados; entre otros, el hecho de que hay gran cantidad de diálogo e introspección, a pesar de que se promocionan como productos de acción. Es el caso de El señor de los cielos que, con tantos capítulos por temporada, necesariamente 
nos adentra en la subjetividad de sus personajes. El amor, eje básico en las telenovelas, también permanece, sólo que, la mayoría de las veces, se ve derrocado por la violencia: Mónica Robles muere en la quinta temporada de El señor de los cielos; Señorita Pólvora y M8 son acribillados; La reina del sur pierde a sus dos amores. Asimismo, aunque podemos vislumbrar una moralidad en el castigo a los villanos, no hay personajes que puedan circunscribirse por completo al polo del bien o del mal, sino, al contrario, fluctúan entre ambos. Estos quiebres con el melodrama nos hacen rechazar su categorización como narcotelenovelas y desligarnos, así de los análisis cualitativos previos.

Por otro lado, en las series: "it is the group of characters and the possibilities of their interaction that drive the actions in the plot" (Huisman 177). Las introspecciones tendrían un menor peso, pues lo relevante serían las acciones de los personajes, tal como se promocionan los productos objeto de nuestro análisis. En ese sentido, la serie permitiría una cierta flexibilidad en cuanto a tópicos, al ser: "un formato complejo y heterogéneo en el que debemos incluir temáticas y contenidos muy diversos que van desde la acción hasta el misterio y la intriga" (Carrasco 187). En cuanto a sus características estructurales se considera que son: "an ongoing story, told in serial fashion from week to week [...] each episode ends with an implicit "to be continued" and in that sense is potentially a never-ending story" (Carroll 19). Unidad argumental y temática, formación episódica y predilección por las acciones serían, así, algunos de sus rasgos más destacados.

Por estas razones, consideramos pertinente adoptar el término de series para estos productos, aunado al hecho de que las telenovelas suelen presentarse en una sola exhibición de 120 capítulos y 50 minutos de duración, estandarizado (Mazziotti). Al contrario, este tipo de series, aunque puedan pensarse originalmente como telenovelas unitarias, según el rating agregan temporadas, como pudimos observar con El señor de los cielos (Aurelio Casillas, ficción de Armando Carillo Fuentes, sobrevive a la cirugía plástica); La reina del sur (su segunda temporada comenzó ocho años después de su primera emisión), La viuda negra (con dos temporadas, hasta ahora); Sin tetas si hay paraíso, entre otras. Para nuestra 
encuesta, sin embargo, no utilizamos el neologismo "narcoseries", pues evaluamos que puede ser portador de una carga semántica negativa, en contraposición a la clasificación de series sobre narcotráfico.

\section{b) Acerca de la construcción de la encuesta}

Elegimos difundir nuestra encuesta, a través de google doc, con la finalidad de constituir una muestra aleatoria y anónima. La encuesta fue de tipo semiestructurada, difundida a través de redes sociales y permaneció abierta durante dos semanas (desde el 9 al 23 de abril del 2019), en las cuales logramos reunir 260 respuestas. Al ser publicada en redes (Facebook, Instagram y Twitter), buscábamos llegar a un público universitario -considerando como tal, licenciaturas y posgrados- cuyo rango de edad oscilara entre los 18 y 40 años, aunque alcanzamos a personas mayores y menores a lo establecido. Esta muestra es de tipo no probabilístico sesgado a cierto grupo: universitario, con acceso a internet y, por ello, de estrato social medio. A pesar de que no incluimos la pregunta acerca de grupo socioeconómico, se infiere que los encuestados tienen ciertos elementos con los que no cuenta toda la población, como computador, celular o Tablet para ingresar a internet.

Como se señaló anteriormente, buscamos que los encuestados se sintieran en total libertad de plantear su verdadera opinión respecto a los productos televisivos, cuyo tema central es el narcotráfico, por ello la elección del léxico “series sobre narcotráfico", el anonimato y la modalidad de encuesta. En la misma línea, buscamos construir preguntas no dirigidas y que, a la vez, nos dieran luces acerca de la cantidad de personas que ven este tipo de productos, la frecuencia con que las consumen y las principales reflexiones y conclusiones que obtienen de ellas. Para alcanzar nuestro objetivo incluimos preguntas cerradas y abiertas.

Dentro del primer grupo agregamos: género (hombre, mujer, otro); edad (menos de 18, 18-24, 25-40, más de 41); escolaridad (primaria, secundaria, preparatoria/bachillerato, licenciatura, posgrado); religión (católico, no creyente, otro); ocupación actual; nacionalidad; lugar de residencia; ¿Cuáles has visto? 
(según nuestro objetivo sólo consideramos series cuya trama principal fuera el narcotráfico en México, aunque dejamos abierto para que agregaran otras, si así lo querían $^{2}$ ); ¿Has visto alguna completa? (sí, no); ¿En qué plataformas las ves? (televisión abierta, televisión por cable, Streaming, Youtube, DVD, páginas de internet); ¿Con quién has visto series sobre narcotráfico? (solo, pareja, hijos, amigos, familiar).

Dentro de las preguntas abiertas incluimos: ¿Por qué ves series sobre narcotráfico? (en este apartado, buscamos determinar gratificaciones y usos que dan a los espectadores); ¿Cuál o cuáles son tus personajes favoritos?; ¿Por qué? (con ambas interrogantes queríamos probar si existe algún grado de identificación con los personajes y saber qué atributos rescatan de ellos) ¿Cómo calificas el rol de las instituciones públicas (policías, militares, gobernantes) como personajes de las series sobre narcotráfico? (bueno, malo, regular, otro); ¿Por qué? (su finalidad fue evaluar la imagen que proyectan las series sobre narcotráfico respecto a las instituciones públicas); Después de ver una serie sobre narcotráfico ¿qué opinas de estas? (la última pregunta pretendía inferir si los encuestados extraen alguna enseñanza o valor de este tipo de productos).

\section{Resultados}

\section{a) Datos generales de la población encuestada}

La categoría de género no arrojó resultados concluyentes respecto a un predominio de espectadores hombres (45\%) o mujeres (55\%). Ello permite vislumbrar que estamos ante un producto sin sesgo de género, que se aleja, tanto de las telenovelas clásicas que apelaban a un público femenino, dueñas de casa y que se transmitían durante todo el día en México (Trejo); así como, a las series de acción, consideradas masculinas y transmitidas en horario nocturno.

2 Nos parece pertinente aclarar que incluimos sólo aquellas series cuyo tema central es el narcotráfico y no aquellas en las cuales funciona como telón de fondo. Nos apoyamos en la diferencia realizada por Daniela Renjel, quien distingue entre: "las de contorno narco y las de contexto narco, que serían las narcotelenovelas propiamente dichas, es decir, las que tratan de una temática cualquiera, generalmente amorosa, en un contexto "narco", y las que tienen como parte estructural de la trama el tema del tráfico de cocaína u otros estupefacientes" (94). 
Al ser una encuesta difundida por redes sociales y en un contexto universitario, obtuvimos respuestas mayoritarias en el rango de edad que va desde los 18 a los $24(36.2 \%)$ y desde los 25 a los 40 años (35.8\%), correspondiente a jóvenes y jóvenes adultos. Tuvimos una escasa respuesta entre los menores de 18 (8.1\%) y mayores de 41 (20\%). Estos resultados son coherentes con la forma de difusión de la encuesta, sin embargo, no permiten deducciones en términos de público objetivo de series sobre narcotráfico. No obstante, buscamos apuntar a este rango de edad, pues para los detractores de estos productos, serían los jóvenes aquel público vulnerable e influenciable por los contenidos transmitidos en televisión (Gutiérrez y Ponce).

En cuanto al nivel de escolaridad el $60.4 \%$ de los encuestados afirmó tener el título de licenciado/a o estar estudiando la licenciatura y el 11.9\% tener o estar estudiando un posgrado, lo que concuerda con la difusión del instrumento en un ámbito universitario. 9.2\% de nuestros encuestados señalaron ser profesores. $\mathrm{Si}$ bien, no incluimos la pregunta respecto al nivel socioeconómico, del grado de escolaridad y profesión, inferimos que la encuesta fue contestada, principalmente, por un sector de clase media, con estudios universitarios, lo que no permite extraer conclusiones respecto a las gratificaciones de los espectadores, según las comparaciones entre clases sociales.

La pregunta acerca de la religión de los encuestados proponía indagar si es que ello pudiera influenciar la percepción respecto a las series sobre narcotráfico. Sin embargo, no hubo conclusiones relevantes, pues son consumidas tanto por católicos (52.3\%), creyentes (11.2\%) como por no creyentes (36.5\%). Asimismo, la encuesta fue respondida por más del 93\% de mexicanos, cumpliendo con el propósito de enfocarnos en esta población. Gran parte vive actualmente en la Ciudad de México (59.6\%) o Estado de México (11.5\%), no obstante, las preguntas fueron respondidas por gente de toda la República (28.9\%).

Ante la pregunta de ¿cuáles has visto?, como señalamos anteriormente, buscamos circunscribir las respuestas hacia series cuya trama principal fuera la industria del narco en México. Así, las más populares resultaron ser: La reina del 
sur (48.5\%), El señor de los cielos (43.8\%) y El chapo (40\%). En el apartado "Otros", varios encuestados respondieron haber visto regularmente las colombianas El patrón del mal y Sin tetas no hay paraíso, y la estadounidense Breaking Bad. La popularidad de estas series sobre narcotráfico se reafirmó con la pregunta acerca de la fidelidad de los espectadores: el $60.4 \%$ de los encuestados admitió haberlas visto completas.

En relación a las plataformas en que los encuestados acceden a este tipo de programas, predominó la visualización a través de Streaming (79.6\%), seguido de televisión abierta $(21.9 \%)$ y televisión de paga (20.8\%). Esto refiere a un interés por las series sobre narcotráfico, ya que, entre tantas opciones de series y películas en estos medios de paga, los espectadores las escogen para verla, tanto en soledad (49.6\%) como en compañía de la familia (37.7\%), la pareja $(25.4 \%)$ o amigos $(10.8 \%)$.

b) Usos y gratificaciones de las series sobre narcotráfico

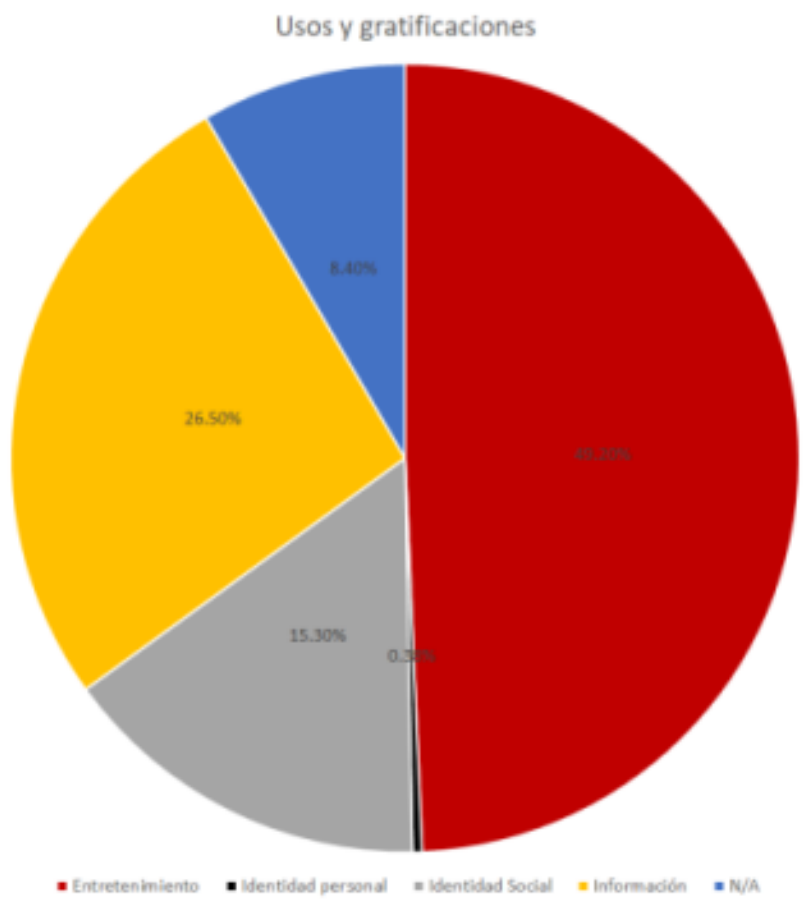

Fuente: elaboración propia 
La pregunta ¿Por qué ves las series sobre narcotráfico?, respondió a la necesidad de establecer un acercamiento a los usos y gratificaciones de los espectadores frente a estos productos, tanto de quienes las consumen de manera regular como de quienes sólo tuvieron un breve acercamiento con estas. Para ello nos basamos en la idea propuesta por Denis McQuail, quien distingue cuatro variables: información, identidad personal, identidad social y entretenimiento.

La gratificación que mayor porcentaje tuvo fue la de entretenimiento (49.2\%), lo que no resulta extraño si pensamos que es un producto popular que mezcla acción y romance. Sin embargo, la matriz de información (26.5\%) también tuvo un alto porcentaje, con respuestas que abarcaron la intención de conocer lo que está ocurriendo en México, la vida de los narcotraficantes y los vínculos de la mafia con el poder político. Algunas de las respuestas fueron: "Por la percepción sociocultural y política de los nexos con el narcotráfico y la proyección que se tiene a nivel mundial del problema"; "Curiosidad sobre el estilo de vida de los narcos, su relación con los problemas de violencia en el país, conocer sus razones o qué los orilló a tomar ese camino"; "Porque muestra una realidad en la que vivimos los mexicanos y que se vuelve parte del común colectivo de la sociedad".

En cuanto a la identidad social (15.3\%) consideramos aquellas respuestas que tuvieron relación con establecer una sociabilización. Entre las más comunes encontramos: "por moda", "me la recomendaron", "alguien de mi familia la estaba viendo", "para tener de qué hablar". En cambio, la matriz de identidad personal casi no se encontró en estas respuestas $(0.38 \%)$, pues los encuestados no sugirieron verlas para sacar conclusiones (positivas ni negativas) respecto a su propia vida o confirmar valores personales. Incluimos, así, sólo un comentario en que se hace relación a la violencia de estas producciones y lo desagradable que al encuestado le parecen. En un $8.4 \%$ los encuestados dijeron no verlas (N/A).

Finalmente, algunas de las respuestas fueron transversales a más de una variable de gratificación: "no me llamaban nada la atención las series porque se me hace un gran problema la narcocultura. Comencé a ver Narcos México sólo porque 
graban en la prepa dónde estudié y me gustó mucho la manera en la que abordan el tema, además que desde que la vi siento que me percaté de lo importante que es saber la historia del narco para entender la historia de México". En esta repuesta, por ejemplo, vemos la reticencia ante el producto, el acercamiento por un hecho personal, el gusto que desarrolla por la serie y la gratificación en términos de información.

\section{c) Atributos de los personajes}

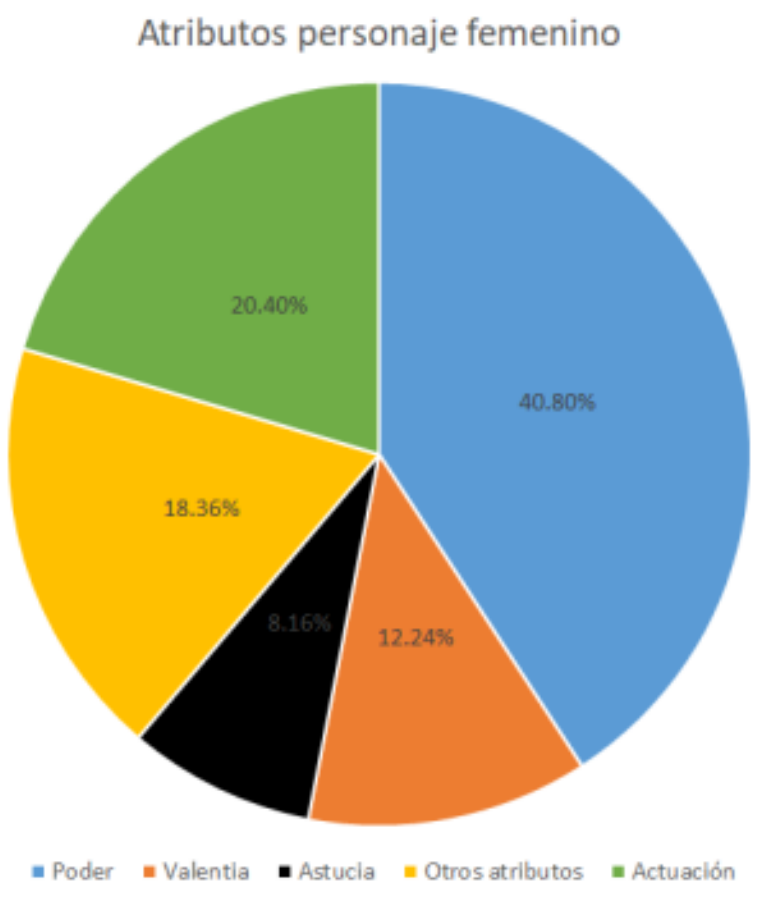




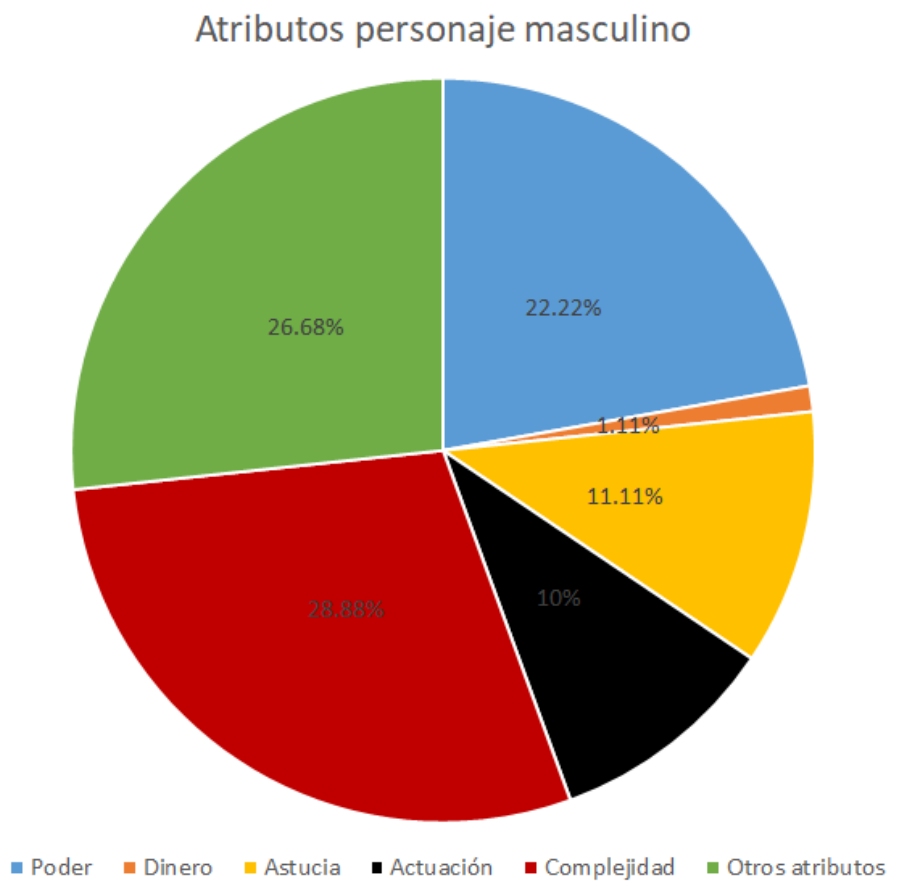

Fuente: elaboración propia

A través de la pregunta ¿Cuál o cuáles son tus personajes favoritos? intentamos indagar acerca de la identificación que podrían tener los espectadores con estos personajes, así como entender qué atributos rescatan de ellos, sin embargo, un porcentaje alto respondió que no tenía (37\%). Aquellos que respondieron de manera favorable, mencionaron en orden de importancia a El Chapo (El Chapo y El Chema), Teresa Mendoza (La reina del sur), Aurelio Casillas (El señor de los cielos), Rosario Tijeras y Pablo Escobar (El patrón del mal y Narcos Colombia).

Para efectos prácticos, y con intención de sacar ciertas conclusiones sobre género, dividimos personajes favoritos femeninos y masculinos. Así, el 18.84\% mencionaron algún personaje femenino como su favorito: Teresa Mendoza en la cima (57.14\%), junto a Rosario Tijeras $(32.65 \%) \mathrm{y}$, en menor medida a otras (10.2\%), como Mónica Robles (El señor de los cielos) y Emilia Urquiza (Ingobernable). En cuanto a los atributos se destaca, principalmente, su poder, a través de adjetivos como: empoderada, poderosa, fuerte y líder (40.8\%); aunque, 
también, se rescata la valentía: atrevida, osada (12.24\%) y la astucia: hábil, lista, inteligente $(8.16 \%)$, entre otras cualidades (18.36\%). Algunos encuestados $(20.40 \%)$ indicaron que sólo les atrae la actuación de las protagonistas. Es de destacar que no hubo ninguna respuesta referida al atractivo de las protagonistas en términos de considerarlas objeto sexual o querer ser como ellas físicamente.

De la población encuestada, el $34.61 \%$ escogieron a un personaje masculino como favorito, siendo los más mencionados: El Chapo (41.11\%), Aurelio Casillas (21.11\%) y Pablo Escobar (11.11\%). Entre otros personajes (26.66\%) destaca Félix Gallardo (Narcos México) y los protagonistas de Breaking Bad. Al contrario de los atributos destacados en los personajes femeninos (en el que predomina poder/empoderamiento), las cualidades que se rescatan de los masculinos son más variados: complejidad (28.88\%), en términos de evolución del personaje e historia de vida; poder (22.22\%), a través de nociones como: líder, influencia, control; astucia $(11.11 \%)$ mediante adjetivos como inteligente e ingenioso y otros atributos (26.68\%). Sólo un encuestado se refirió al dinero como un valor (1.11\%), mientras, algunos rescataron las actuaciones (10\%).

A diferencia de lo que ocurre con los personajes femeninos, no se menciona la valentía como una característica a destacar entre los protagonistas masculinos, así como en las mujeres no se rescata la evolución del personaje, lo que sí fue muy referido en relación a los personajes hombres. El hecho de que las mujeres fueran definidas en términos de poder/empoderamiento resultaba predecible, pues Teresa Mendoza, Rosario Tijeras, Mónica Robles, Camelia la Texana, entre otras, son representadas desde su agencia y valentía, no obstante, en estas series también los personajes masculinos basan su poder en su arrojo, por lo que resulta curioso que los encuestados no lo mencionaran como una característica. Asimismo, los personajes femeninos también son retratados desde sus orígenes y carencias, por ello es interesante que esta complejidad y evolución no sea algo relevante para los encuestados, como sí parece ser en personajes como El Chapo o Aurelio Casillas. 


\section{d) Rol de las instituciones públicas}

La pregunta: ¿Cómo calificas el rol de las instituciones públicas (policías, militares, gobernantes) dentro de las series sobre narcotráfico?, tuvo mayor cantidad de respuestas negativas referidas en términos de malo $(64.2 \%)$ y regular (28.1\%) y muy pocas positivas (7.7\%). Entre las respuestas positivas cabe señalar que el $30 \%$ consideraron bien realizado el trabajo de la DEA porque vieron Narcos Colombia y Breaking Bad; $25 \%$ respondieron "bueno" refiriéndose a la actuación y representación de los organismos públicos, con base en la realidad: "Porque las autoridades no actúan, porque es real que son así’. De esta manera, sólo el 45\% (del 7.7\%) realmente contestó que el rol de las instituciones públicas, en las series sobre narcotráfico en México, es bueno. De estos, la mayoría (66.6\%) coinciden en haber visto La reina del sur y El Chapo, dos series en que los narcotraficantes son apresados por sus delitos al final de la temporada.

En cuanto a la pregunta del ¿por qué?, existió consenso entre los encuestados, al considerar que representan a las instituciones como corruptas (50\%) o como incompetentes o negligentes (25.38\%), aunque encontramos respuestas en que ambos factores están imbricados: "diría que es malo, puesto que vemos los hechos de corrupción y por ello, se estigmatizan a las instituciones como el papel de quienes no hacen nada, no triunfan, no logran nada contra el cáncer del narco". Asimismo, el 10\% de los encuestados, que mencionan corrupción o incompetencia de los agentes públicos en las series de televisión, también hacen referencia directa a que ello ocurre en la realidad: "porque siempre reflejan la corrupción que se vive en el país", "son corruptos como en la realidad", "nos muestran nuestra triste realidad, corrupción total", "aparentan que estas instituciones hacen su trabajo, cuando en realidad son igual o más cerdos que los narcos. Y son los que joden más a la gente".

Estas respuestas resultan coherentes con la percepción que tiene la ciudadanía, es por ello que la corrupción e incompetencia tienden a ser evaluadas en términos de realidad. Tal como propone Oswaldo Zavala en su libro Los cárteles no existen, la apreciación general de la sociedad es que nuestros gobernantes no 
sólo están coludidos con el narcotráfico sino que son responsables directos de su existencia: "el narco en México no sólo no antagoniza con el Estado, sino que es en realidad el resultado de una operación política y judicial dirigida desde el mismo Estado que estructura y a la vez limita el mercado ilícito de estupefacientes" (170). Esta sería la idea que refuerzan las series sobre narcotráfico, convirtiéndose en un reflejo de lo que se considera es corrupción e impunidad por parte de las autoridades.

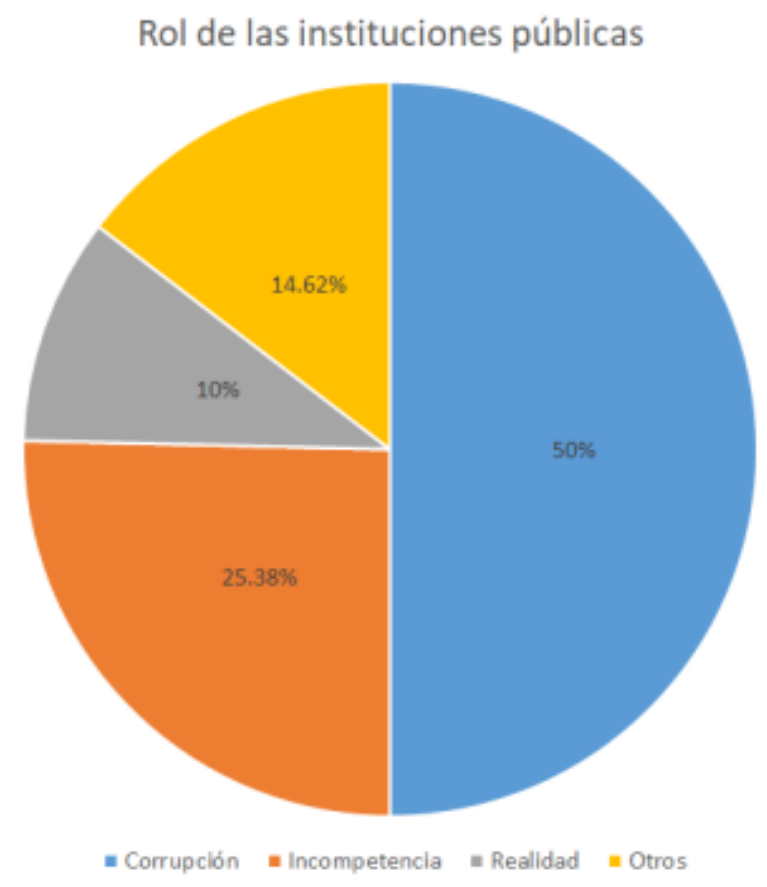

Fuente: elaboración propia

\section{e) Series sobre narcotráfico: opiniones y reflexiones}

La última pregunta: Después de ver una serie sobre narcotráfico ¿qué opinas de estas?, intentó contrarrestar o complementar el pensamiento que los encuestados manifestaron en la primera pregunta abierta, ¿Por qué ves series sobre narcotráfico? Así, buscamos comprobar si existía algún cambio en torno a los usos y gratificaciones de los espectadores, según la pregunta realizada y el orden de esta. 
Este fue el segmento en el que mayormente se explayaron los encuestados, dando opiniones muy diversas. Mantuvimos las matrices de entretenimiento e información y agregamos componentes negativos como violencia y apología al delito. La variable de reflexión la utilizamos para casos en que los encuestados definieron haber inferido algún componente moral, alguna lección o enseñanza. En ese sentido, se vincula a la matriz de identidad personal que no se desarrolló en la pregunta ¿Por qué las ves?

Aunque, nuevamente, primó la idea de que son productos hechos para el entretenimiento (33.07\%), el uso como fuente de información se mantuvo bastante alto $(28.80 \%)$, ya que, en muchas respuestas se señala que las series sobre narcotráfico son un medio de acceso a la historia y la actualidad mexicana: "ejemplifican lo complejo de la realidad", "ayudan a tener una mejor perspectiva sobre el tema", "tienen un valor cultural", "qué chido que alguien tenga el valor de mostrar un poco el lado oscuro del país", "es una buena manera de exponer la situación en el país”. Algunas de las respuestas, incluso, profundizan y discuten, pues consideran que en algunas series se evidencia una ideología estadounidense al representar a Latinoamérica como un lugar que debe ser salvado: "me choca que las series son super paternalistas y ponen a los agentes de la DEA como los salvadores de Latinoamérica y nos pintan como la barbarie". Asimismo, se retoma la idea de que estas series critican la corrupción gubernamental: "es una crítica al gobierno y a la sociedad en sí”.

En cuanto a las concepciones negativas de estas series, tenemos aquellas que piensan que son un productos que realiza una apología al delito (18.84\%) o que solamente son violencia innecesaria (3.07\%). Sin embargo, un rasgo a destacar es que, incluso, quienes presentan una visión muy negativa de las series, quienes las consideran dañinas, extraen conclusiones muy razonadas sobre la sociedad mexicana, la corrupción imperante y el problema del narcotráfico: "Es triste, porque responden a una realidad y es muy peligroso porque romantizan muchísimo la vida de un narco, he escuchado a gente más joven, que no vive en pobreza o en una situación extrema que los obligue a trabajar en ello, a querer unirse al narco y nadar 
en dinero", "Está bien informar a la gente, pero igual está mal que la juventud utilice esto para hacer moda y querer ser como ellos, es algo tonto querer estar entre tantos conflictos"

Hay un espíritu crítico en las respuestas que no se queda sólo en la entretención que produce, lo que, por supuesto, puede estar mediado por el espectro poblacional elegido. Sin embargo, y a pesar de ser una muestra bastante sesgada, refiere a espectadores activos que se sienten interpelados de manera crítica por el producto televisivo. De la respuesta anterior, por ejemplo, inferimos que el encuestado considera que estas series informan: "está bien informar a la gente", aunque cree que puede haber gente que quiera volverse narco por moda: "está mal que la juventud utilice esto para hacer moda y querer ser como ellos". Finalmente, también rescata que no es una vida digna de imitar: "es algo tonto querer estar entre tantos conflictos".

Así, aunque en la pregunta acerca de usos y gratificaciones no encontramos respuestas que refirieran directamente a la identidad personal, en este apartado sí tenemos reflexiones $(9.61 \%)$ en que los encuestados desprenden conclusiones morales de estas series: "llevar una vida así implica demasiado peligro", "Es triste ver cómo la gente no tiene amor propio y expone a sus familias por unos pesos mal ganados a costa de muertes", "Que es un negocio muy sucio y machista", "Que es increíble como naturalizamos la violencia. Exponen el tema del narcotráfico tan abiertamente porque todos sabemos cómo se maneja junto con la política, pero no se hace nada al respecto. Sólo aprendemos a soportar el descaro y abandono por parte de los gobiernos", "Me gustan porque me dan elementos para analizar la realidad, creo que ésta supera a la ficción", "Lo malo termina mal siempre se juega con todo y al final termina sin triunfo", "Es interesante cómo al final de cuentas tienen todo (económicamente) pero no tienen nada (respeto, dignidad)", "La mayoría reflejan muchas cosas de la realidad dejando una pequeña reflexión, quien se mete en el narcotráfico nunca sale bien librado". 


\section{Opinión sobre series de narcotrafico}

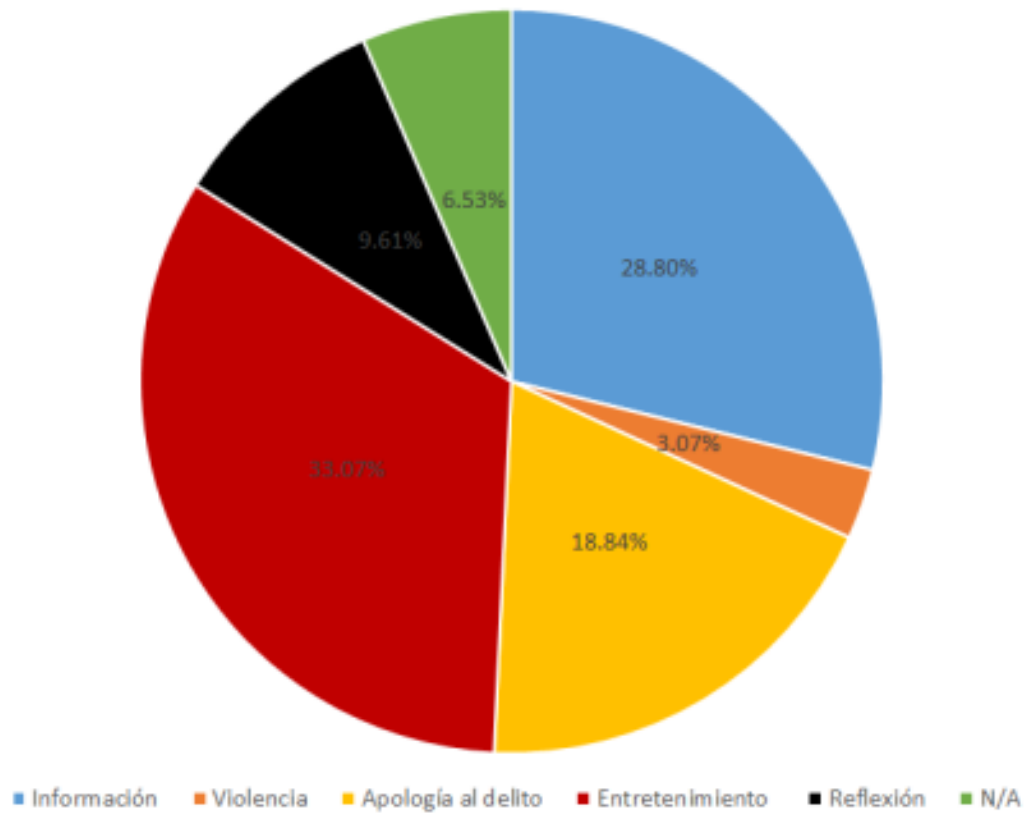

Fuente: elaboración propia

\section{Conclusiones}

Como equipo, estamos conscientes de que esta encuesta fue de tipo no probabilístico sesgado y, por ello, sumamente limitada en sus alcances. Al contrario de otros análisis cualitativos en Latinoamérica, dejamos de lado variables que pueden ser relevantes, tales como el nivel socioeconómico y el nivel de escolaridad, así como las edades de los consumidores. Al hacerla circular por redes sociales, apuntamos a un público de clase media o clase alta y fue contestada por estudiantes y profesores, principalmente. Será fundamental en el futuro comprender, también, los valores y enseñanzas que reciben niños y adultos mayores, respecto a estos productos. Lo dejamos, entonces, como una tarea pendiente y asumimos que nuestros resultados responden a una escolaridad, edad y nivel socioeconómico determinado por el ámbito universitario en que difundimos nuestro instrumento.

Dicho esto, nos parece interesante rescatar como conclusión que, a pesar de que muchos encuestados consideran que este tipo de series realizan una apología al crimen y son dañinas por el nivel de violencia que presentan, logran extraer críticas 
no sólo de este tipo de productos sino de la realidad en la que viven. Hace unos años, Epigmenio Ibarra -director de la productora Argos y responsable de éxitos como El Señor de los Cielos- comentaba en una entrevista a RT que su intención era generar contenidos comerciales que, a la vez, permitieran reflexionar acerca del país: "Si las telenovelas sirven para idiotizar también pueden servir para despertar a la gente [...] Esa es nuestra pretensión. Que después de cada episodio [...] tú te preguntes y ¿yo qué? y le preguntes a tu pareja ¿y nosotros qué? y te preguntes por el país y te digas ¿dónde estamos?” (en línea), una pregunta que, efectivamente, prima en las respuestas obtenidas mediante esta encuesta.

Incluso, aquellos encuestados que asumen no ver este tipo de series, expresan su opinión en torno al México que se representa y logran vislumbrar una crítica a la corrupción e ineficiencia de las autoridades. Así, estaríamos ante un producto que trasciende lo meramente comercial y de entretenimiento para contribuir en el debate acerca del estado actual del país y que, en cierto sentido, es utilizado por los espectadores como fuente de información para conocer y tratar de entender esta problemática que afecta a toda la población.

En esta línea, esta encuesta presenta resultados muy diferentes a los anteriores estudios cualitativos, puesto que concluimos que gran parte de los televidentes no se identifican con los personajes de estas series, no buscan imitar sus acciones ni elevan a los narcotraficantes al rango de héroes, sino que acceden a estos productos desde una visión crítica respecto a la realidad mexicana actual, cuestionando el papel de los gobiernos y sus instituciones en este contexto. Asimismo, son capaces de extraer lecciones morales de estos productos ("Lo malo termina mal", "quien se mete en el narcotráfico nunca sale bien librado"), tal como descubrimos en la última pregunta de la encuesta.

Nos parece importante, así, apuntalar que las series sobre narcotráfico no pueden ser catalogadas, de manera rígida, como productos dañinos, sino que también es posible encontrar en ellos mensajes positivos. Con ello queremos indicar la importancia de no satanizar a la industria del entretenimiento y, al contrario, intentar desentrañar y valorar los aspectos de gratificación en el público. En este 
caso, rescatamos que permiten a los espectadores reflexionar sobre lo que está ocurriendo en México, lo que puede constituir un primer paso para imaginar en el futuro un escenario diferente.

\section{Bibliografía}

Aguirre, Lina. "Sin tetas no hay paraíso: normalización del cuerpo femenino en el mundo del narcotráfico". Taller de Letras 48 (2011): 121-128.

Cárdenas, Claudia. Estudio de casos: Influencia de las narconovelas en el pensamiento y comportamiento de estudiantes adolescentes de dos colegios del cantón Cuenca. Diss. Universidad de Cuenca, 2016.

Carrasco, Ángel. "Teleseries: géneros y formatos. Ensayo de definiciones". Miguel Hernández Communication Journal 1 (2010): 174-200.

Carroll, Noel. "TV and Film: A Philosophical Perspective". The Journal of Aesthetic Education 35(2001): 15-29.

Gutiérrez, Víctor y Ponce, Fausto. "La guerra contra las narcoseries". $E l$ Economista (2016) https://www.eleconomista.com.mx/arteseideas/Laguerra-contra-las-narcoseries-20161031-0097.html 31 octubre 2016.

Huisman, Rosemary. "Soap Operas and Sitcoms". Narrative and Media. Helen Fulton, editora. Cambridge: Cambridge University Press, 2005. 172-188.

López, Karla; Vaque, Johanna y Arias, Christian. "La influencia de las narco novelas en el consumo de drogas en adolescentes". Revista Caribeña de Ciencias Sociales 4 (2019):

https://www.eumed.net/rev/caribe/2019/04/influencia-narconovelas.html

Manrique, Ximena. La narco novela como publicidad de violencia en los jóvenes colombianos. La era del Patrón. Diss. Pontificia Universidad Javeriana, 2014.

Martínez, Danixa y León, María Fernanda. Análisis semiótico de la narco-novela "El señor de los cielos" y su impacto en jóvenes de 15 a 17 años de edad de la Calle M entre la 16 y 17 de Guayaquil. Diss. Universidad de Guayaquil, 2019.

Mazziotti, Nora. "Introducción. Acercamiento a las telenovelas latinoamericanas". Nora Mazziotti, editora. El espectáculo de la pasión: las telenovelas latinoamericanas. Buenos Aires: Colihue, 1993. 11-27.

McQuail, Denis. Mass Communication Theory: an Introduction. London: Sage Publications, 1983. 
Monroy, Martha Luz y Cabrera, Wilmar. "El escándalo gana rating”. El tiempo (2006) https://www.eltiempo.com/archivo/documento/MAM-2161292 26 agosto 2006.

Montoya, Jennifer; Guarín, John y García, Jhon. Narco contenidos: Recepción y mediación imagen de barrio, de los estudiantes de la Institución Educativa Gonzalo Mejía Echeverry. Diss. Universidad Tecnológica de Pereira, 2011.

Moreno, Jenny. La recepción de narcotelenovelas por jóvenes de la ciudad de Bogotá. Diss. Universidad de Barcelona, 2016.

Pérez, Laura. Análisis de los discursos y contenidos de las narco novelas y el impacto que estas han tenido en los niños de 15 a 17 años que habitan en el sur de Quito. Diss. Universidad Politécnica Salesiana Sede Quito, 2013.

Pobutsky, Aldona. "Deleitar denunciando: La narco telenovela de Gustavo Bolívar Sin tetas no hay paraíso marca el pulso de la sociedad colombiana". Espéculo: Revista de Estudios Literarios 46 (2010). http://webs.ucm.es/info/especulo/numero46/deleitar.html

Renjel, Daniela. "Gustavo Bolívar: el hombre de las narcotelenovelas". Mitologías Hoy 14 (2016): 93-111.

RT en Español. Entrevista con Epigmenio Ibarra. Estados Unidos: RT, 2014. https://www.youtube.com/watch? $\mathrm{v}=\mathrm{jP} \_$p0c63yOk\&amp $=\& \mathrm{t}=656 \mathrm{~s}$

Sánchez, Alejandro y García, Valentina. La representación de la masculinidad, el poder y los modelos de vida en la narrativa de la narco telenovela "El cártel de los sapos" y la valoración de los jóvenes universitarios de la Pontificia Universidad Javeriana Cali. Diss. Pontificia Universidad Javeriana, 2015.

Trejo, Marcia. La telenovela mexicana. Orígenes, características, análisis y perspectivas. Ciudad de México: Trillas, 2011.

Zavala, Oswaldo. Los cárteles no existen. Narcotráfico y cultura en México. Barcelona: Malpaso, 2018.

$(\mathrm{cc}) \mathbf{E Y}$

ULSS D-Sonfe
New articles in this journal are licensed under a Creative Commons Attribution 4.0 United States License. 